\title{
Evaluation of the effectiveness of forms of organization of automated workstations
}

\author{
Ivan Savin ${ }^{1, *}$, Sergey Sienko ${ }^{1}$, and Boris Zhadanovsky ${ }^{1}$ \\ ${ }^{1}$ Moscow State University of Civil Engineering (MGSU), 26, Yaroslavskoye Shosse, Moscow, Russia
}

\begin{abstract}
Fast and efficient collection, processing and storage of huge amounts of information has become the main condition for the successful functioning of modern organizations, institutions and enterprises. The increasing rates of informatization of society increase the importance of computer technology in management processes. Using the capabilities of modern computing technology to automate the information processing process allows you to increase labor productivity, improve the efficiency of working with documents and speed up the exchange of information. At present, the concept of local information processing has become widespread. This allows you to organize the division of labor of personnel and automate the performance of their functions. To implement this idea, it is necessary to create workplaces for each level of management and each subject area, including remote ones. In the information economy, the successful promotion of an organization in the market is impossible without presenting the results of assessing the expected efficiency of automation. Evaluation of the effectiveness of the use of automated "virtual" workplaces is an ambiguous and multi-criteria process. Due to the huge variety of enterprises and the conditions in which they operate, options for automating activities, it is impossible to define standards, benchmarks. Each organization solves this issue independently, comparing with analogs.
\end{abstract}

\section{Introduction}

The introduction of remote workplaces, the so-called "virtual" (equipped with computing facilities and data transmission facilities, which, based on the use of software, methodological and informational support, makes it possible to automate analytical calculations and transfer their results) implies that the main operations for the accumulation, storage and processing of information are entrusted to computer technology, and the user performs some of the manual operations and operations that require a creative approach in the preparation of certain solutions, therefore such workplaces must be considered as an amplifier of human intellectual capabilities and a universal means of information processing.

The increasing rates of informatization of society increase the importance of computer technology in management processes. This allows organizing the division of labor of personnel and automating the performance of their functions. To implement this idea, it is necessary to create automated workplaces for each level of management and each subject

\footnotetext{
*Corresponding author: savin.vanya2013@gmail.com
} 
area. We are talking about a complex of technical and software - a tool for any user. Workplaces, created to implement specific functions, is called functional. They can be subdivided by the type of user activity: economist, technologist, designer, administrator, accountant, etc.

Let's present a diagram of an automated "virtual” workplace in Figure 1.

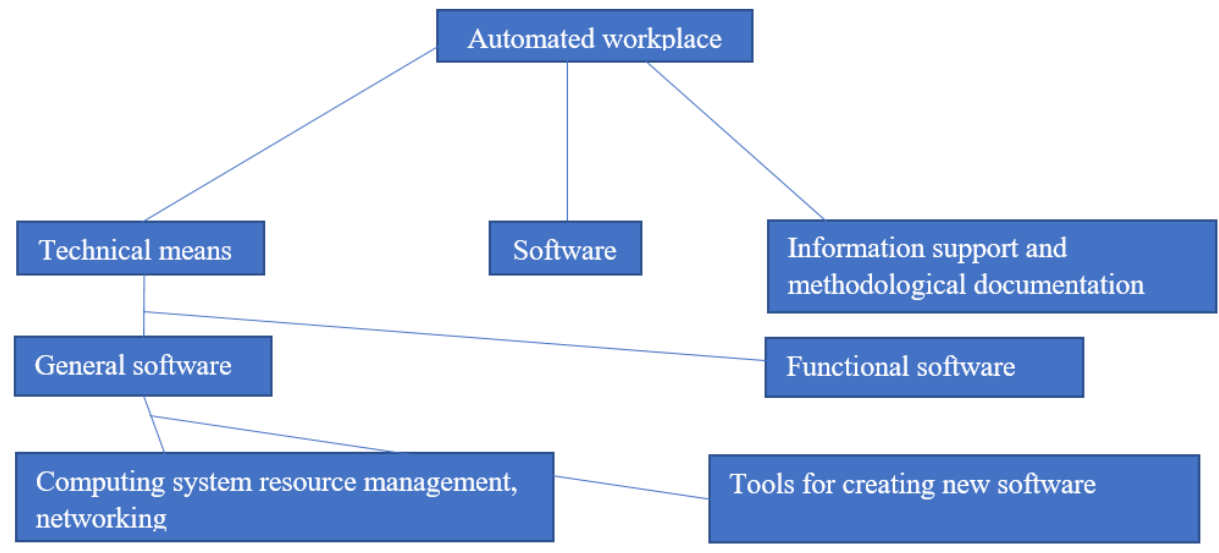

Fig. 1. Virtual workplace organization diagram.

The role of an automated "virtual" workplace is determined by the nature of their participation in the management process of a particular area of production activity. The function of an automated "virtual" workplace consists in the implementation of subject technology - a sequence of stages of modifying primary information into resultant information, through information technology.

You can classify an automated "virtual" workplace:

- by functional purpose,

-by the types of tasks to be solved,

- according to the mode of operation.

Automated "virtual" workplaces have a problem-professional orientation to a specific subject area. An important classification feature of automated "virtual" workstations is its operating mode, according to which single, group and network operating modes are distinguished.

\section{Materials and methods}

Let's consider the main elements of automated "virtual" workplaces - information, software and hardware.

Information support of automated "virtual" workplaces, its data bank is a display of information arrays and flows of the corresponding subject area, for which automated "virtual" workplaces are designed. The databank is intended for entering, storing and updating data on specific objects of the subject area, such as various economic indicators, regulatory and reference information, etc. In addition, the databank must contain information that provides the User Dialogue of automated "virtual" workstations from a PC: lists of dialogue scenarios, forms of input and output documents, instructions, etc. In other words, it is a kind of information model of the subject area.

The software for automated "virtual" workstations is an integrated application system designed to provide a solution to the problems facing a specialist in a specific application area. Three main parts can be distinguished: system-wide software, general-purpose 
software, and problem-oriented software. In addition, it can include as an optional element (in cases where users of the first and second categories are among the users of automated "virtual" workstations) the software of the users.

Software is closely related to the mathematical support of automated "virtual" workstations. In many areas of practice, including commercial, economic and mathematical modeling is not yet widely used, despite the huge economic effect that it can bring. This is due not so much to the inability of practical workers to use economic and mathematical methods (although this factor cannot be ignored), but to the impossibility of their application in the absence of computer technology. The development of a variety of automated "virtual" workstations and the inclusion of various programs to overcome these difficulties. If at first the software of automated "virtual" workplaces mainly automates the functions performed by users, transferring their daily repetitive actions to machine language, then subsequent development should follow the path of modeling the processes occurring in this subject area, and this entails the expansion of automated "virtual" workplaces [1]. Hardware is also an important element of automated "virtual" workstations, since its capabilities are largely determined by the computers on which it is implemented.

Each specific subject area, naturally, imposes its specific requirements on the automated "virtual" workstation used in it.

\section{Results}

The urgency of the problem of assessing the effectiveness of the organization of an automated workplace is also emphasized by the fact that the costs of developing and implementing automated "virtual" workplaces, as a rule, are much higher than planned, and managers often do not dare to create automated "virtual" workplaces without performance evaluation. The development and implementation of projects of automated "virtual" workplaces are associated with investments, investment of funds, the cost of working time and labor. The monetary costs of automation represent the capital costs of developing and implementing a project and operating costs [2].

It is also advisable to take into account the costs of human labor for the performance of the listed works, especially the time of workers performing them without additional payment during their working hours.

Savings in information processing costs using automated "virtual" workstations are calculated comparing the costs of information processing for at least two options [3]. The payback period of the project of automated "virtual" workplaces is calculated by dividing the amount of capital costs by the savings in information processing costs or by the annual increase in profit.

There are also a number of indirect indicators of the effectiveness of automated "virtual" workplaces, which are reflected in the results of production and economic activities by increasing the level of management, efficiency of decisions made, that is, indirectly. These include, namely:

- increasing the efficiency and relevance of information;

- shortening the time for solving individual problems and making management decisions;

- improving the quality of information, its accuracy, detail;

- obtaining fundamentally new analytical capabilities;

- reducing the amount of time spent on preparing documents, the speed of issuing output documents;

- improving the quality of customer service and the percentage of retention of old customers;

- reduction of accounts receivable due to automatic tracking of issued invoices, payment terms, debt repayment; 
- control effort, abuse prevention;

- the effect of reducing the impact of staff turnover on production indicators;

- improving the quality of work by reducing routine operations;

- improvement of the work of the management apparatus.

The economic efficiency of automated "virtual" workplaces is determined by the savings resulting from the more active influence of managers on production and the costs of creating and operating automated workplaces. It is possible to assess the effectiveness of the use of automated "virtual" workplaces using direct and indirect indicators. Direct (or economic) indicators assess automation in monetary terms, include determining the costs of developing and operating automated "virtual" workplaces (i.e., determining the total cost of ownership of an automated "virtual" workplace), determining the cash flow released at the expense of automated "virtual" workstations. Indirect indicators allow us to assess the effect of the use of automated "virtual" workplaces in a specific subject area of activity (Table 1) [4].

Table 1. Potential effect of using automated workstations.

\begin{tabular}{|l|l|}
\hline Scope of influence & Result \\
\hline Management & - reducing the number of management levels; \\
- reduction of administrative expenses; \\
- the release of middle management workers and the abolition of a \\
number of functions; \\
- release of workers from routine work due to its automation; - freeing \\
up time for intellectual activity; \\
- obtaining rational methods for solving management problems through \\
the introduction of mathematical methods and intelligent systems; \\
- increasing labor productivity; \\
- saving time; \\
- advanced training and professional literacy of managers; \\
- increasing competitive advantage; \\
- cost reduction, profit increase
\end{tabular}

The efficiency of automated "virtual" workplaces includes not only the economic effect of the implementation and operation of automated "virtual" workplaces, but also such characteristics as reliability, ease of use, ease of modification, replicability of engineering solutions, and reduction in development and operation costs.

Therefore, the process of increasing the efficiency of automated "virtual" workplaces should begin with increasing the efficiency of the development of automated "virtual" workplaces. 
The nature of the future automated "virtual" workplace is determined by the initial stages of the project cycle. Any mistake or miscalculation during this period causes great losses in the future. Table 2 provides data on the ratio of risk and costs during the implementation of the project to create an automated "virtual" workplace (Table 2) [5].

Table 2. Dependence between the amount of resources involved in the project and the risk of creating the wrong workstation.

\begin{tabular}{|l|c|c|}
\hline \multicolumn{1}{|c|}{ Project stage } & Risk level & Costs \\
\hline Identifying the problem & 100 & 0 \\
\hline Baseline study & 90 & 5 \\
\hline Project planning & 75 & 15 \\
\hline Sketch design & 50 & 25 \\
\hline Engineering design & 40 & 30 \\
\hline System implementation planning & 20 & 40 \\
\hline Programming & 15 & 70 \\
\hline Personnel training & 15 & 75 \\
\hline System test & 10 & 80 \\
\hline Implementation & 5 & 99 \\
\hline System performance evaluation & 0 & 100 \\
\hline
\end{tabular}

The experimental relationship between the amount of resources involved in the project and the degree of risk of creating an incorrect automated "virtual" workplace (Fig. 1.2) shows that the success of the project is predetermined mainly at the stages of research on the possibility of creating automated "virtual" workplaces and technical design, when small additional investment can reduce the likelihood of error. To reduce risk, the initial steps are broken down into as many small, well-measured and controlled steps as possible. The costs of such a division in the future will pay off by saving resources and reducing development time.

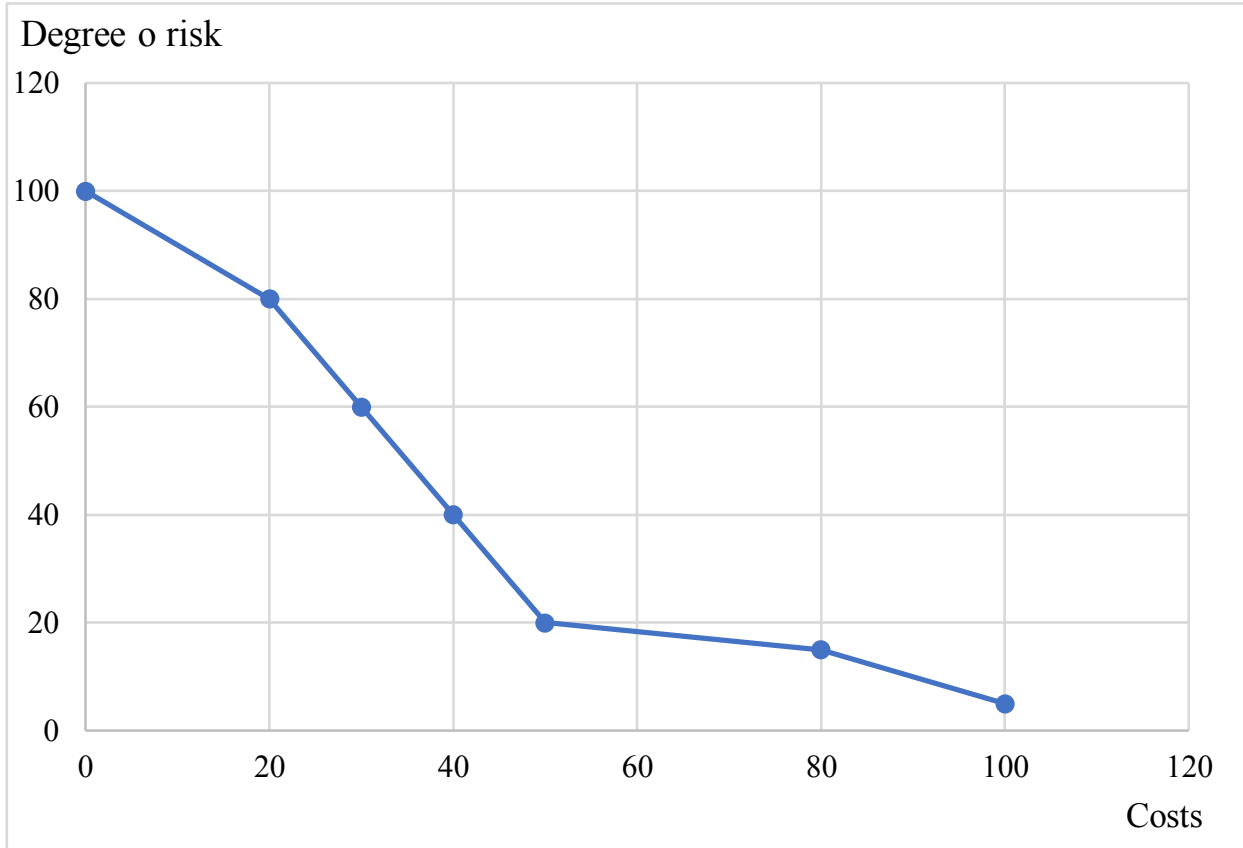

Fig. 2. Dependence between the amount of people involved in the project resources and the degree of risk of creating wrong workstation. 
An important condition for increasing the efficiency of automated "virtual" workplaces is a well-established practice of their operation. This can significantly reduce the total cost of ownership of automated "virtual" desktops, which in many cases is critical when implementing automated "virtual" desktops in an organization. Effective operation of automated "virtual" workplaces should be built on the basis of procedures developed and approved as internal corporate or industry standards. There are the following standards for the operation of automated "virtual" workstations, namely:

- server hardware standards;

- data storage standard;

- e-mail standard;

- document exchange standard;

- internal technical support standard;

- other.

The system of standards allows you to save the investments made in automated "virtual" workplaces and get real returns from them. Discussion, development, improvement of internal corporate standards is the second stage, and at the first stage it is necessary to implement as widely as possible the standard of using automated "virtual" workplaces.

Increasing efficiency requires not only observing the most important properties of automated "virtual" workplaces during their development, but also the implementation of a set of interrelated and interdependent organizational measures:

- improving the structure and form of interaction between developers and customers of automated "virtual" workstations;

- introduction of a system of standards for technical, ergonomic, operational parameters of automated "virtual" workstations, which allows to preserve the investments made in information technologies and get real returns;

- improving the forms and methods of training a wide range of specialists in the use of automation tools.

Automated "virtual" workplaces as a tool for rationalizing and intensifying management activities are created to ensure the performance of a certain group of functions. The simplest function of automated "virtual" workstations is information and reference services. Although this function is to some extent inherent in any automated "virtual" workstation, the features of its implementation significantly depend on the category of the user. A prerequisite for the creation of automated "virtual" workplaces is the availability of a technical base, a database on the economic activities of an enterprise, a knowledge base (methods and methods of analysis) and software that automate the solution of analytical problems [6].

Creation of automated "virtual" workplaces for an analyst requires solving many organizational issues related to methodological, technical, software and information support. The software is divided into general and functional. General software includes the operating system, service programs, programming systems, software tools, problem-oriented application programs [7].

Software tools can be of different types: text and graphic editors for preparing texts, graphs, diagrams, spreadsheet processors or spreadsheets for automated processing of information presented in tabular form, database management systems for automating work on creating a database, searching for the necessary information for analytical calculations. Integrated packages include text and graphics editors, spreadsheet, etc. [8]

At the first stage of creating automated "virtual" workplaces for analysts, as a rule, local programs are used, designed for multiple solutions of the same type of tasks.

At the second stage, a comprehensive analysis program is developed that covers all aspects of the enterprise and includes a whole system of interrelated tasks. For its development it is required, namely $[9,10,11]$ :

1) formulation and description of the tasks of complex economic analysis; 
2) development of algorithms and models for solving problems, that is, a mathematical description of problems;

3) development of a new information system, creation of a data bank;

4) development of computer programs in algorithmic languages;

5) introduction of automated "virtual" workstations for production management.

\section{Conclusions}

Practical experience of using automated "virtual" workplaces as one of the elements of distributed control systems allows us to highlight the following requirements for an efficiently and fully functioning automated workplace, namely:

- timely satisfaction of the user's information needs;

- the minimum response time to user requests;

- adaptation to the level of training of the user and the specifics of the functions performed by him;

- the ability to quickly teach the user basic techniques;

- reliability and ease of maintenance;

- friendly interface ("common border" between individual systems through which they interact; a set of tools and rules that ensure the interaction of individual systems (for example, a person, software, hardware, etc.);

- the ability to work as part of a computer network.

The increasing rates of informatization of society increase the importance of computer technology in management processes. Using the capabilities of modern computing technology to automate the information processing process can increase labor productivity, improve the efficiency of work with documents and speed up the exchange of management information.

\section{References}

1. I.V. Miroshnik, Automatic control theory. Linear systems (Business literature, M., 2009)

2. D. O'Leary, ERP system. Modern planning and resource management of the enterprise $(\mathrm{SPb}, 2009)$

3. S.M. Patrushina, Information systems in economics (Business Publishing House, Moscow, 2010)

4. V.V. Repin, V.G. Eliferov, Process approach to management. Business process modeling (Standards and Quality, Moscow, 2009)

5. S. Sinenko, I. Savin, E3S Web Conf. International Scientific and Practical Conference "Environmental Risks and Safety in Mechanical Engineering" 217 (2020)

6. Ya.A. Khetagurov, Design of automated information processing and control systems (ASOIU) (OLMA-press, M., 2010)

7. S. Sinenko, IOP Conf. Series: Earth and Environmental Science 459, 052043 (2020) IOP doi: 10.1088 / 1755-1315 / 459/5/052043

8. D. O'Leary, ERP-systems: selection, implementation, operation. Modern planning and resource management of the enterprise (Vershina, M., 2009)

9. S. Sinenko, T. Poznakhirko, V. Obodnikov, 2018 MATEC Web of Conferences 270, 05008 (2019) https: //doi.org/10.1051/matecconf/201927005008

10. M.N. Ershov, A.A. Lapidus, V.I. Telichenko, Technological processes in construction in 10 books. Textbook (2016) 